\title{
Influence of Attitude on Technology, Perceived Benefits and Perceived Risks on Stakeholders' Attitude towards Outdoor Residual Spraying
}

\author{
Ahmad Firdhaus Arham ${ }^{1 *}$, Latifah Amin ${ }^{1,2 *}$, Muhammad Adzran \\ Che Mustapa', Zurina Mahadi', and Mashitoh Yaacob' \\ ${ }^{1}$ Pusat Citra Universiti, Universiti Kebangsaan Malaysia, \\ Malaysia, 43600 UKM Bangi, Selangor, Malaysia. \\ ${ }^{2}$ The Institute of Islam Hadhari (HADHARI), Universiti Kebangsaan \\ Malaysia, 43600 UKM Bangi, Selangor, Malaysia.
}

\section{ABSTRACT}

Objectives: The goal of this paper is to analyze the influence of attitude to technology, perceived benefits and perceived risks on stakeholders' attitude towards ORS. This method needs support from stakeholders so that its implementation does not cause any concern. Design/Methodology/Approach: In order to achieve the desired goal, questionnaires were built on the basis of a validated study. The questionnaires were distributed randomly on three hundred and ninetynine adult respondents above 18 years old (scientists and the public who reside in the dengue hot-spot areas around the Klang Valley) from September 2016 to September 2017. The data that has been collected, is then analyzed using structural equation modeling with partial least squares (PLS) approach. Results: Perceived benefits was found to be the most important and strongest direct predictor of positive attitude to ORS. It also acted as mediator for the relationship between perceived risks and attitudes to technology with attitude to ORS. Perceived risks also served as a mediator for attitudes to technology. Limitations: The data collected only covers two groups of stakeholders. In fact, only three predictor factors were evaluated to determine the influence of attitudes on the ORS method as one of the control of dengue in Malaysia. Future studies may use various predictive factors in determining attitude towards other dengue control techniques. Practical implications: These findings can provide an insight into the social acceptance of ORS technology to combat dengue. Originality/Value: Authors confirm that this study and the findings are genuine and have not yet been released. The proposed structural model in this study serves as a basis for improving the decision-making process of ORS technology.

KEY WORDS: OUTDOOR RESIDUAL SPRAYING; ATTITUDE; PERCEIVED BENEFITS; PERCEIVED RISKS; ATTITUDE TOWARDS TECHNOLOGY.

\section{ARTICLE INFORMATION}

Corresponding author email: benferdaoz@ukm.edu.my

Received 30th Oct 2020 Accepted after revision 13th Dec 2020

Print ISSN: 0974-6455 Online ISSN: 2321-4007 CODEN: BBRCBA

Thomson Reuters ISI Web of Science Clarivate Analytics USA and Crossref Indexed Journal

$$
\underset{\text { Analytics }}{\text { Clarivate }}
$$

NAAS Journal Score 2020 (4.31)

A Society of Science and Nature Publication,

Bhopal India 2020. All rights reserved.

Online Contents Available at: http//www.bbrc.in/

Doi: http://dx.doi.org/10.21786/bbrc/13.15/14

\section{INTRODUCTION}

The outdoor residual spraying (ORS) approach is an efficient insecticide-based control to reduce the population of Aedes (Lee et al., 2015). Rozilawati et al. (2005) demonstrated that this approach was successful in controlling the Aedes population, especially in areas where the density was high and preventive measures just could not be carried out. The findings of Ab. Hamid et al. (2019) have shown that ORS is a good approach to control dengue in the outdoor areas because it is a

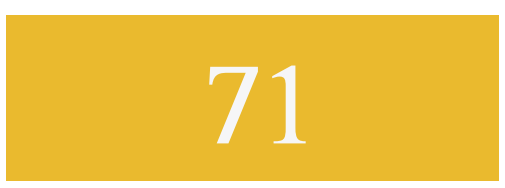


successful method, if carried out correctly. The use of the ORS is durable and naturally resistant to rain (Lee et al., 2015) causing this insecticide to remain long on the surface of the sprayed wall to trap mosquitoes that rest on the sprayed area. Nevertheless, the efficacy of this ORS often relates to the characteristics of the wall surface, the geographical area, the rainfall distribution, the humidity and the intensity of the location.

Previous studies have claimed that residual spraying is successful in reducing the Aedes population, particularly in the densely populated areas in Malaysia (Ab. Hamid et al., 2020, 2019; Rozilawati et al., 2007; Rozilawati et al., 2005). Nonetheless, its implementation has been criticized for giving a "false sense of security" that decreases household participation in prevention activities (Reyes-Castro et al., 2017, Wijayanti et al., 2019). However, the implementation of ORS is one of the wise actions to control the Aedes population, but its implementation depends on social acceptance towards the approach. In fact, it is important to explore the aspects of people's views on technology and whether they feel there is a benefit or a risk in deciding their attitude towards this approach. This research is important in evaluating the need for this approach to control dengue through social acceptance and, then, designing effective policies such that its implementation does not have an effect on environmental health.

Research Conceptual Framework: The research conceptual framework was developed from the study of Amin and Hashim (2015), which was the first assessment in Malaysia that specifically explained the interrelated factors that influence stakeholders' attitudes towards the genetically modified mosquito (GMM). Their findings indicated perceived benefit was the most influential factor of attitudes towards GMM. However, Alhakimi and Slovic (1994) highlighted that perceived benefit and perceived risk were found to be inversely related, which when people tend to judge any technologies high in benefit, they considered low in risk, and vice versa. Therefore, this study also evaluate stakeholder's attitudes toward technology to predict that they perceived benefits or risks on ORS approach. In this study three factors (perceived benefits, perceived risks and attitudes to technology) were predicted to influence stakeholders' attitudes towards the ORS approach (see Figure 1). Six hypotheses were postulated for the relationships between the predictors nad attitude to ORS and among the factors:

Use Standard Hypothesis Statement As In My Past Papers.

H1: Perceived more benefits, they will have more positive attitudes towards the ORS approach.

H2: Perceived more risks, they will have fewer positive on attitudes towards the ORS approach.

H3: Attitudes to technology have positive effect on attitude towards the ORS approach

H4: Perceived more risks, they will perceive fewer benefits associated with ORS approach.

H5: Attitudes to technology have positive effect on perceived benefits
H6: Attitudes to technology have negative effect on perceived risks

Figure 1: Research Conceptual Framework

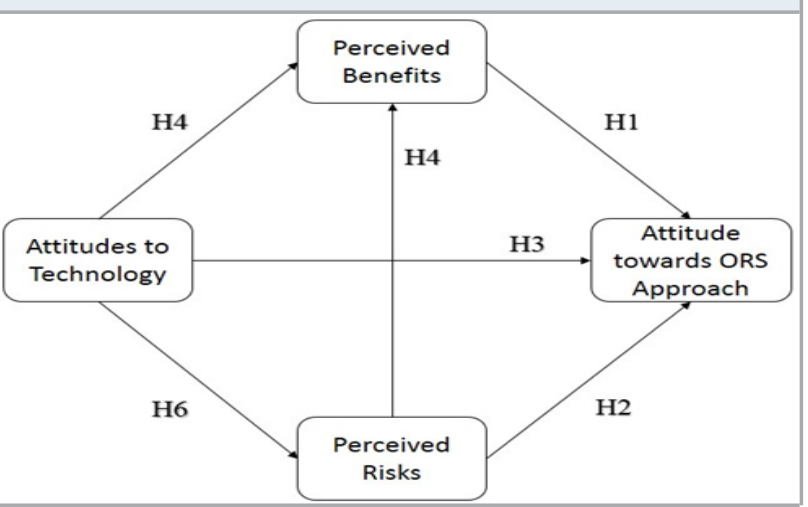

Attitude is commonly described as a thought about something and predetermined views (Kaliyaperumal, 2004) which organizes the direction on their surroundings and guides how they react to it. Lian et al. (2014) proposed that an attitude is the internal behaviour of a person towards an external target and that it was the cause and preparation of a response. DomínguezValerio et al. (2019) highlighted that it is important to shape attitudes because it can affect an individual's final behaviour. There are five items that represent aspects of attitude discussed in this study:

ATO 1: This approach has to be scaled up.

ATO 2: This approach must have more financial support from government.

ATO 3: This approach allows a decrease in the fatalities.

ATO 4: This approach is required.

ATO 5: This approach is encouraged.

According to Amin \& Hashim (2015), perceived benefits was the major significant predictor which influenced attitudes towards GMM. Perceived benefit refers to the user's perception of the beneficial effects of the use of a technology (Park et al., 2014) while perceived risk refers to its negative impacts (Aven \& Renn, 2010). Perceived benefits and risks are highly complex and complicated to conceptualize on a stand-alone basis because these variables often have an inverse correlation (Hansen et al., 2003). Frewer (2017) found out that, when a person sees more benefits related to a technology, the perceived risks tend to be less which results higher acceptance of the technology (Amin et al., 2017). There are seven items that represent perceived benefit (PB) and seven items that represent perceived risk (PR), namely:

PB 1: A valuable approach that improves the quality of life.

PB 2: A valuable approach to Malaysian society.

PB 3: A valuable approach to prevent dengue fever.

PB 4: A valuable approach to the eradication of dengue.

PB 5: A valuable approach that is beneficial to the health 
of me and my family.

PB 6: A valuable approach that benefits more people than it risks.

PB 7: All the risks of the approach will be dealt with in the future

PR 1: The possible unknown consequence of the approach

PR 2: Harmful impact over a long period of time

PR 3: A threat to future generations.

PR 4: Gives rise to unforeseen consequences.

PR 5: It becomes a major disaster for Malaysian society.

PR 6: Future risks to your health and the safety of your family.

PR 7: The adverse effects of the approach are harmful.

Attitudes to technology refer to the evaluation of an individual to accept any technology that also takes into account its negative effects on the environment. People who have a negative view of technology in general tend to perceive a specific application as more risky and have lower benefits (Amin Et Hashim, 2015, Amin et al., 2017). There are six items that represent the attitudes to technology (ATT) discussed in this study, namely:

ATT1: Technology has made humans have less respect for nature.

ATT2: Technology has made humans more focused on profits.

ATT3: Technology has destroyed the value of humanity.

ATT4: Technology has made human beings limitless to the point of losing humanity.

ATT5: Technology has made humans threaten the balance of nature.

ATT6: Technology has made human beings a problem for urban life.

\section{METHODOLOGY}

The research data was collected through a validated questionnaire-based survey that focused on three hundred and ninety-nine adult respondents (aged 18 years and above) by a random sampling strategy from September 2016 to September 2017 in the Klang Valley. The Klang Valley was selected as the site of the research due to its having the highest recorded dengue cases in Malaysia, according to statistics released by the Ministry of Health, Malaysia. G*Power 3.1.9.2 software was used to assess the minimum sample size of the respondents with the statistical power of 0.80 (Faul et al., 2007), the effect size of 0.15 and significance level of less than 0.05. A sample size of two hundred and seventy-seven respondents is suggested for this research. Therefore, respondents were chosen from two groups of stakeholders, including a group of scientists (scholars, researchers and government officers) ( $n=202)$ who engaged in dengue prevention, and a group of the public $(\mathrm{n}=197)$ who were residing in dengue area hotspots in the Klang Valley. Based on empirical research published by Amin Et Hashim (2015), a multidimensional questionnaire was developed to measure attitude towards ORS and its predictive factors.
All items for this survey were assessed using a 7-point Likert scale. The SPSS software version 23.0 was used to record the data. Analysis of the reliability and validity of the data and the association between predictor factors and attitude towards the ORS was carried out using SmartPLS-SEM software version 3.0.

ANALYSIS and Findings: Table 1 presents the demographic information of the three hundred and ninety-nine stakeholders sampled in the Klang Valley >>>Insert Table 1

A. Analysis of the Measurement Model: Table 2 demonstrates the evaluation of the construct reliability and the convergent validity of the constructs in this research. The composite reliability (CR) values of 0.879 (Attitude towards ORS), 0.923 (Perceived Benefits), 0.938 (Perceived Risks) and 0.944 (Attitudes to Technology) demonstrated that these constructs have good internal consistency because the $\mathrm{CR}$ values were greater than 0.7 as suggested by Gefen et al. (2000). The factor loadings were greater than 0.5 and the average variance extracted (AVE) for each construct also reached a minimum threshold value of 0.5 , which implies that the items loaded into the respective constructs contribute more than 50\% of the variances of the construct (Hair et al., 2014). Analysis of the measurement model also evaluated the standardized root means square residual (SRMR) and the normed fit index (NFI). The SRMR value for the model was a perfect fit when the value was 0.066 (below 0.08) as proposed by $\mathrm{Hu}$ and Bentler (1998). The NFI value was 0.831 which is closer to 1 , which defines perfect fit (Dijkstra \& Henseler, 2015).

Fornell-Larcker Criterion and Heterotrait-Monotrait Ratio (HTMT) criterion analyses were measured to assess the discriminant validity (see Table 5). The findings stated that the value of the Fornell-Larcker Criterion in this study had a square root AVE value (diagonal attributes) that reached the total variance associated with the other variables. While the value of HTMT does not exceed 1, it means that all the value at the threshold of HTMTO.90 are distinctly different (Henseler et al., 2015).

$>>>$ Insert Table 2

>>>Insert Table 3

B. Analysis of Path Coefficient: To analyze the significant path of the coefficient and validate the hypotheses that have been developed, the PLS-SEM bootstrapping procedure was used, using an observation data set of 5000 sample cases. Table 4 demonstrates the evaluation of the path coefficient analysis. For H1, the result indicated a positive relationship between perceived benefits and attitude towards ORS $(\beta=0.693 ; t=24.632$; $\mathrm{p}<0.001)$. In contrast, there was no significant association between perceived risks $(\beta=-0.049 ; \mathrm{t}=0.997)$ and attitudes to technology ( $\beta=0.006 ; t=0.121)$ with attitudes towards ORS, indicating no support for $\mathrm{H} 2$ and $\mathrm{H} 3$. However, there is an indirect relationship between peceived risks and attitude to ORS through the perceived benefits. Additionally, perceived risks had a significant negative relationship with perceived benefits $(\beta=-0.166 ; t=22.634$; 
$\mathrm{p}=0.004$ ), so H4 was supported. Attitudes to technology also have a positive influence on the perceived benefits $(\beta=0.175 ; t=3.139 ; p=0.001)$, so H5 was supported.

Figure 2: PLS-SEM of Stakeholders' Attitude towards Outdoor Residual Spraying Approach

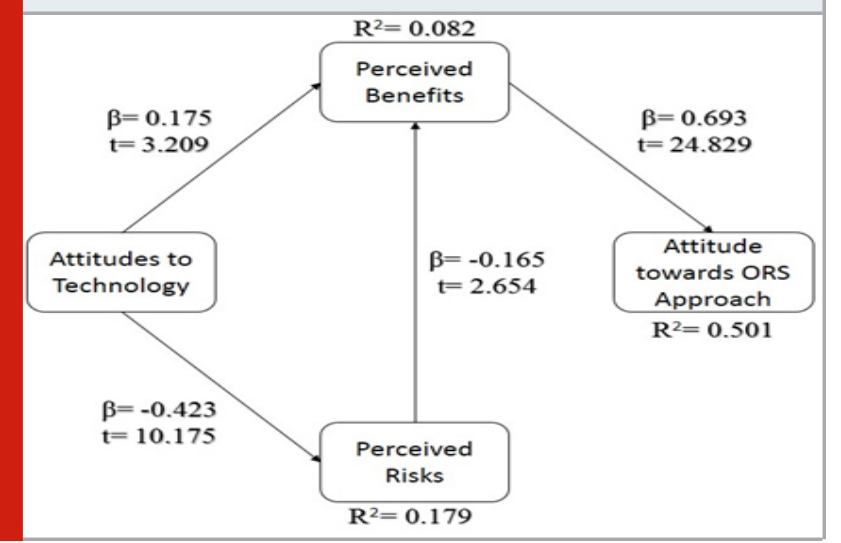

Table 1. Demographic Information

\begin{tabular}{|c|c|c|c|}
\hline $\begin{array}{l}\text { Demographic } \\
\text { Variables }\end{array}$ & & Frequency & Percent \\
\hline \multirow[t]{2}{*}{ Gender } & Male & 195 & $48.9 \%$ \\
\hline & Female & 204 & $51.1 \%$ \\
\hline \multirow{2}{*}{$\begin{array}{l}\text { Types of } \\
\text { Stakeholders }\end{array}$} & Scientist & 197 & $49.4 \%$ \\
\hline & Public & 202 & $50.6 \%$ \\
\hline \multirow[t]{4}{*}{ Level of Education } & $\begin{array}{c}\text { Secondary/ } \\
\text { Pre-University }\end{array}$ & 44 & $11.0 \%$ \\
\hline & Diploma & 56 & $14.0 \%$ \\
\hline & Degree & 163 & $40.9 \%$ \\
\hline & Master and PhD & 136 & $34.1 \%$ \\
\hline \multirow[t]{3}{*}{ Age } & 28-28 years old & 185 & $46.4 \%$ \\
\hline & 29-39 years old & 132 & $33.1 \%$ \\
\hline & $\begin{array}{l}\text { Above } 40 \\
\text { years old }\end{array}$ & 78 & $19.5 \%$ \\
\hline
\end{tabular}

About H6, the results showed that there is a relationship of negative effects between attitudes to technology and perceived risks $(\beta=-0.423 ; t=10.114 ; p<0.001)$. The finding also showed that perceived risks acted as a mediator factor for the relationship between attitudes to technology and perceived benefits. To prove the indirect effect of perceived risks as a mediator, the variance accounted for (VAF) assessment was conducted. The result obtained showed that the value of VAF exceeds $20 \%$ as suggested by Preacher \& Hayes (2008) who explained that perceived risk acted as a mediator factor. The result indicated that, if the respondent was more technologically oriented, the risk of this approach would be ranked as being lower and would result in a higher perceived benefits of ORS.

>>>Insert Table 5
Table 2. Results of Measurement Model

\begin{tabular}{l|l|l|l|l|}
\hline Measurement Item & Loading & CR & AVE & Validity \\
\hline Perceived Benefits & & & & \\
PB1 & 0.768 & 0.923 & 0.632 & YES \\
PB2 & 0.794 & & & \\
PB3 & 0.837 & & & \\
PB4 & 0.849 & & & \\
PB5 & 0.798 & & & \\
PB6 & 0.757 & & & \\
PB7 & 0.755 & & & \\
\hline Perceived Risks & & 0.938 & 0.684 & YES \\
PR1 & 0.683 & & & \\
PR2 & 0.825 & & & \\
PR3 & 0.848 & & & \\
PR4 & 0.881 & & & \\
PR5 & 0.835 & & & \\
PR6 & 0.826 & & & \\
PR7 & 0.876 & & & \\
\hline Attitudes to & & 0.944 & 0.737 & YES \\
Technology & & & & \\
ATT1 & 0.770 & & & \\
ATT2 & 0.859 & & & \\
ATT3 & 0.893 & & & \\
ATT4 & 0.903 & & & \\
ATT5 & 0.901 & & & \\
ATT6 & 0.818 & & & \\
\hline Attitude towards & & 0.879 & 0.594 & YES \\
ORS & & & & \\
AT01 & 0.729 & & & \\
AT02 & & & \\
AT03 & & & \\
AT04 & & & \\
AT05 & & & \\
\hline
\end{tabular}

C. Analysis of the Structural Model: The analysis of the structural model also involves calculation for the coefficient determination (R2) in which the well-fitting model must have $\mathrm{R} 2$ values from zero to 1 . The $\mathrm{R} 2$ values ranged from 0.082 to 0.501 , suggesting that the exogenous variables could explain $8.2 \%$ to $50.1 \%$ of the variance of the respective endogenous variables as suggested by Yap et al. (2018). The analysis also involved measuring for the effect size (f2) on the impact value of the exogenous variables on the endogenous variables. Perceived benefit ( $\mathrm{f} 2=0.882$ ) has a large effect size on attitude towards the ORS approach, while the effect size of attitude to technology ( $\mathrm{f} 2=0.027$ ) and perceived risk ( $f 2=0.024$ ) on perceived benefit was small. However, attitude to technology ( $f 2=0.218$ ) has a medium effect size on the perceived risk. The analysis for the accuracy of the model predictions (Q2) was also carried out. The Q2 values for perceived benefit (0.050), perceived risk $(0.120)$ and attitude towards the ORS approach (0.284) were completely accurate as they were higher than zero (Fornell, 1994). 


\begin{tabular}{|c|c|c|c|c|}
\hline Fornell-Larcker Criterion & ATO & ATT & PB & PR \\
\hline Attitude towards ORS & 0.77 & & & \\
\hline Attitudes to Technology & 0.196 & 0.859 & & \\
\hline Perceived Benefits & 0.706 & 0.245 & 0.795 & \\
\hline Perceived Risks & -0.216 & -0.423 & -0.239 & 0.827 \\
\hline HTMT criterion & ATO & ATT & PB & PR \\
\hline \multicolumn{5}{|l|}{ Attitude towards ORS } \\
\hline Attitudes to Technology & 0.232 & & & \\
\hline Perceived Benefits & 0.79 & 0.259 & & \\
\hline Perceived Risks & 0.232 & 0.451 & 0.246 & \\
\hline
\end{tabular}

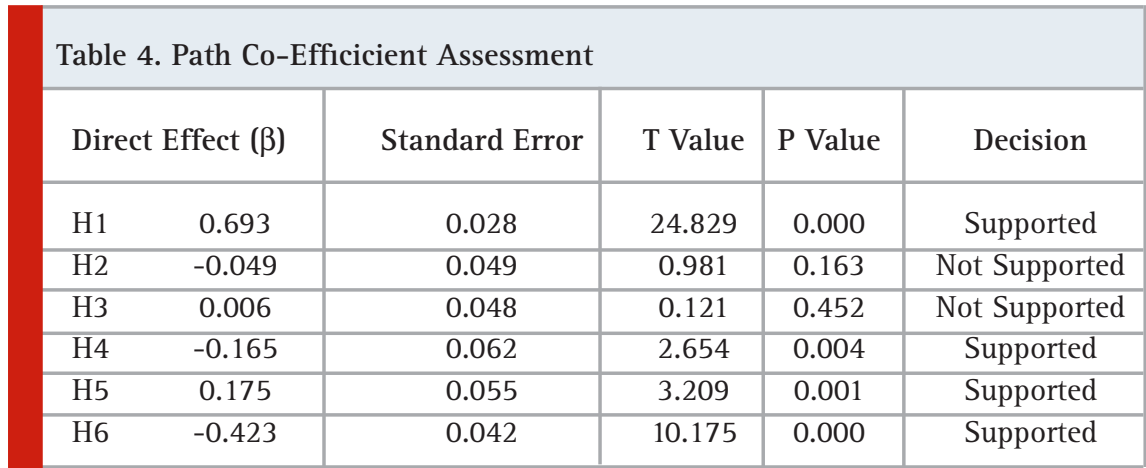

\section{DISCUSSION AND CONCLUSION}

The contribution of this study is important in determining the social acceptance of stakeholders towards the ORS in the Klang Valley area which is known to have a very high case of dengue. First, this study has successfully developed a valid model of the factors that influence attitudes towards ORS (see Figure 2). Perceived benefits is the only factor that directly influences the attitude to ORS. This study is in line with the findings of Amin and Hashim (2015) who studied the influence of perceived benefits on attitude to GMM and Arham et al. (2020) who confirmed that the perceived benefits is a major factor in influencing attitudes towards Wolbachia-infected Aedes Mosquitoes in Klang Valley.

The study also found that perceived risks had an indirect relationship with the attitude towards ORS through perceived benefits. This explains that when the stakeholders judged ORS as having high risk, they will assess the method as possessing lower benefits, thus were less positive towards ORS. These findings differs from the study of Amin and Hashim (2015) who showed that there is no relationship between perceived risk and benefit.

Additionally, there is a positive relationship between attitudes to technology with perceived benefits and negative relationship with perceived risk. Amin and Hashim (2015) stated that attitudes towards technology (negative) have a positive relationship with perceived moral concerns. This study is in line with the study of Amin et. (2005) which showed that when respondents have a negative tendency towards science and technology they will feel the risk and has a high level of moral concern. On the other hand in this study, although they have a negative tendency towards technology, they feel the benefits and less risk of ORS technology. It is possible that this technology does not pose any danger to environmental health. Arham et al. (2020) suggested that if they have a more positive view towards technology, they would have a positive attitude. It can be concluded that in order for the ORS method to be acceptable to the Malaysian stakeholders, the government and scientists need to increase public awareness on the benefits of ORS and proper safety measures be introduced to ensure environmental sustainability.

\section{ACKNOWLEDGEMENTS}

The authors would thank all respondents who have participated in this research. The research was financially supported by Universiti Kebangsaan Malaysia under the MI-2020-010 and ERGS/1/2013/SSI12/UKM/02/1 grants.

\section{REFERENCES}

Ab Hamid, N., Mohd Noor, S. N., Susubi, J., Isa, N. R., Md Rodzay, R., Bachtiar Effendi, A. M., Hafisool, A. A., Azman, F. A., Abdullah, S. F., Kamarul Zaman, M. K., Wasi Ahmad, N., \&t Lee, H. L. (2020). Semifield evaluation of the bio-efficacy of two different deltamethrin formulations against Aedes species in an outdoor residual spraying study. Heliyon. 6(1), e03230. 
https://doi.org/10.1016/j.heliyon.2020.e03230

Ab Hamid, N., Mohd Noor, S.N., Saadatian-Elahi, M., Isa, N.R., Md Rodzay, R., Md Ruslan, B., Omar, T., Mohd Norsham, M.I., Amanzuri, N.H., Abd Khalil, N., Zambari, I.F., Mohd Kassim, M.A., Kamarul Zaman, M.K., Bachtiar Effendi, A.M., Hafisool, A.A., Peng, L.T., Poong, B., Ibrahim, M., Roslan, N.A., Lim, L.H., 2019. Residual spray for the control of Aedes vectors in dengue outbreak residential areas. Advances in Entomology. 7(4), 105-123. DOI: 10.4236/ae.2019.74009

Alhakami, A.S., Slovic, P., 1994. A psychological study of the inverse relationship between perceived risk and perceived benefit. Risk Analysis, 14(6): 1085-1096.

Amin, L., Arham, A.F., Mahadi, Z., Razman, M.R., Rusly, N.S., 2019. Sikap Pihak Berkepentingan terhadap Teknik Fogging di Malaysia (Stakeholder's Attitude towards Fogging Technique in Malaysia). Akademika. 89(2), 187-200.

Amin, L., Hashim, H., Mahadi, Z., Ibrahim, M., Ismail, K., 2017. Determinants of stakeholders' attitudes towards biodiesel. Biotechnology for Biofuels. 10, 219. https:// doi.org/10.1186/s13068-017-0908-8

Amin, L., Hashim, H., 2015. Factors influencing stakeholders' attitudes toward genetically modified aedes mosquito. Science and Engineering Ethics. 21(3), 655-681. https://doi.org/10.1007/s11948-014-9557-5 Amin, L., Md Jahi, J., Md. Nor. A.R., Osman, M., Mahadi, N.M., 2005. Relationship between general attitude towards nature religion, custom, science and technological progress and attitude towards modern biotechnology. Malaysian Journal of Environmental Management. 6, 73-86.

Arham, A.F., Amin, L., Mustapa, M.C.A., Mahadi, Z., Arham, A.F., Yaacob, M., Ibrahim, M., Norizan, N.S., 2020. Perceived benefits and risks: A survey data set towards Wolbachia-infected Aedes Mosquitoes in Klang Valley. Data in Brief. 32, 106262, 1-6. https://doi. org/10.1016/j.dib.2020.106262.

Arham, A.F., Amin, L., Mahadi, Z., Yaacob, M., Razman, M.R., 2020. Predicting factors and attitude towards Wolbachia-infected Aedes mosquitoes in Malaysia. Academy of Strategic Management Journal. 19(2), 1-5.

Aven T, Renn 0., 2010. Risk Management and Governance. Springer Verlag; New York, NY, USA.

Dijkstra, T.K., Henseler, J., 2015. Consistent and Asymptotically Normal PLS Estimators for Linear Structural Equations, Computational Statistics \& Data Analysis. 81(1): 10-23.

Dominguez-Valerio, C.M., Moral-Cuadra, S., MedinaViruel, M.J., Orgaz-Agüera, F., 2019. Attitude as a Mediator between Sustainable Behaviour and Sustainable Knowledge: An Approximation through a
Case Study in the Dominican Republic. Social Science. 8, 288.

Faul, F., Erdfelder, E., Lang, A-G., Buchner, A., 2007. G*Power 3: A Flexible Statistical Power Analysis Program for The Social, Behavioral, and Biomedical Resources. Behavior Research Methods. 39, 175-191.

Fornell, C., Cha, J., 1994. Partial Least Squares. Advanced Methods of Marketing Research. 407, 52-78.

Frewer, L.J., 2017. Consumer acceptance and rejection of emerging agrifood technologies and their applications. European Review of Agricultural Economics, 44(4), 683-704.

Gefen, D., Straub, D., Boudreau, M-C., 2000. Structural equation modeling and regression: guidelines for research practice. Communications of the Association for Information Systems. 2(1), 7.

Hair, J.F., Sarstedt, M., Hopkins, L., Kuppelwieser, V.G., 2014. Partial least squares structural equation modeling (PLS-SEM): An emerging tool in business research. European Business Review. 26(2), 106-121.

Hansen, J., Holm, L., Frewer, L., Robinson, P., Sandøe, P., 2003. Beyond the knowledge deficit: recent research into lay and expert attitudes to food risks. Appetite. 41(2), 111-121. https://doi.org/10.1016/s01956663(03)00079-5

Henseler, J., Ringle, C. M., Sarstedt, M., 2015. A new criterion for assessing discriminant validity in variancebased structural equation modeling. Journal of the Academy of Marketing Science. 43(1), 115-135.

Hu, L., Bentler, P.M., 1988. Fit indices in covariance structure modeling: sensitivity to underparameterized model misspecification. Psychological Methods. 3(4), 424-453.

Kaliyaperumal, K.I.E.C., 2004. Guideline for conducting a knowledge, attitude and practice (KAP) study. AECS Illumination. 4(1), 7-9.

Lee, H.L., Rohani, A., Khadri, M.S., Nazni, W.A., Rozilawati, H., Nurulhusna, A.H. Nor Afizah, A.H., Roziah, A., Rosilawati, R., The, C.H., 2015. Dengue Vector Control in Malaysia-Challenges and Recent Advanced. International Medical Journal Malaysia. 14(1), 11-16.

Lian, J.W., Yen, D.C., Wang, Y.T. 2014. An exploratory study to understand the critical factors affecting the decision to adopt cloud computing in Taiwan hospital. International Journal of Information Management. 34: 28-36.

Park, J.-G., Park, K., Lee, J., 2014. A firm's postadoption behavior: loyalty or switching costs? Industrial Management \& Data Systems. 114(2), 258-275. https:// doi.org/10.1108/IMDS-06-2013-0259

Preacher, K.J., Hayes, A.F., 2008. Asymptotic and resampling strategies for assessing and comparing 
indirect effects in multiple mediator models. Behavior Research Methods. 40(3), 879-891.

Reyes-Castro, P.A., Castro-Luque, L., Díaz-Caravantes, R., Walker, K.R., Hayden, M.H., Ernst, K.C., 2017. Outdoor spatial spraying against dengue: A false sense of security among inhabitants of Hermosillo, Mexico. PLOS Neglected Tropical Diseases. 11(5): e0005611. https://doi.org/10.1371/journal.pntd.0005611

Rozilawati, H., Zairi, J., Adanan, C.R., 2007. Seasonal abundance of Aedes albopictus in selected urban and suburban areas in Penang, Malaysia. Tropical Biomedicine. 24(1), 83-94.

Rozilawati, H., Lee, H.L., Mohd Masri, S., Mohd Noor, I. and Rosman, S., 2005. Field bioefficacy of deltamethrin residual spraying against dengue vectors Medical Entomology Unit, Institute for Medical Research, Jalan
Pahang, 50588 Kuala Lumpur, Malaysia. Tropical Biomedicine. 22(2), 143-148.

Sultan, N., 2013. Knowledge management in the age of cloud computing and Web 2.0: Experiencing the power of disruptive innovations. International Journal of Information Management. 33(1): 160-165.

Wijayanti, S.P.M., Octaviana, D., Nurlaela, S., 2019. False Sense Security Effect of Outdoor Spatial Spraying Against Dengue : A Household Survey in Endemic Area, Indonesia. Annals of Tropical Medicine and Public Health. 18, 1002-1021.

Yap, B.W., Ramayah, T., Nushazelin Wan Shahidan, W.N. 2012. Satisfaction and trust on customer loyalty: a PLS approach, Business Strategy Series. 13(4): 154167. https://doi.org/10.1108/17515631211246221 